\title{
Fall Prevention: \\ Home Safety Inventory ${ }^{1}$
}

IFAS EXTENSION

Leigh Ann Martin ${ }^{2}$

Homes you've lived in most of your life can cause problems as you age.

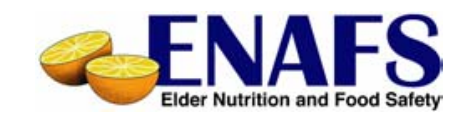

Use this inventory to find possible problem areas. Skip any that don't apply to you. If you answer "no" to any of the questions, make the needed change(s) as soon as possible.

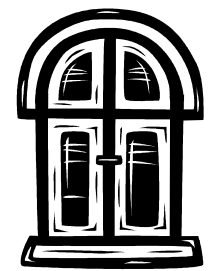

\section{Windows and Doors}

Are windows and doors easy to open and close?

Yes

No

Are door thresholds low and easy to step over?

Is there space to maneuver while opening and closing the door?

Yes

No

Does the front door have a peephole at the right height for you?

Yes

No

Floor Surfaces

Floor Surfaces

Are all surfaces non-slip?

Are rugs and doormats tacked down?

Yes

No

Are floor level changes well marked?

Yes No

\section{Steps and Stairways}

Do you have handrails on both sides of the stairway? Are stair treads deep enough for your whole foot?

\section{Kitchen and Bath}

Can you sit while working in the kitchen?

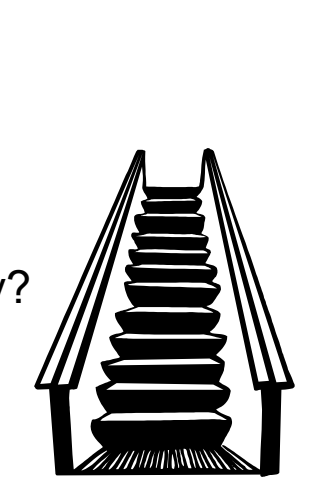

Yes

No

Can you get into and out of the tub or shower with ease?

Yes

No

Do you have a rubber mat in your bathtub or shower?

Do you have grab bars in the bathroom?

Yes No

Yes No

Yes No

\section{Electrical Outlets and Switches}

Are outlets and switches easy to turn on and off? $\quad$ Yes No

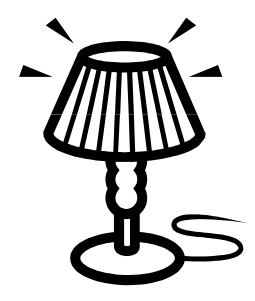

Are extension cords in good condition?

Yes No

Is the telephone easily available in case of an emergency?

Yes No

\section{Lighting}

Do you have adequate lighting throughout the house?

Do you have nightlights where needed?

Yes No

Yes No

1. This document is FCS2229, one in a series of the Department of Family, Youth and Community Sciences, Florida Cooperative Extension Service, Institute of Food and Agricultural Sciences, University of Florida, Gainesville, FL 32611. Publication date: April 2005. Please visit the EDIS Website at http://edis.ifas.ufl.edu

2. Leigh Ann Martin, MS, former assistant-in, Department of Family, Youth and Community Sciences, Institute of Food and Agricultural Sciences, University of Florida, Gainesville, FL 32611. Reviewed by Linda B. Bobroff, PhD, RD, LD/N, and Kristen Smith, MS, Department of Family, Youth and Community Sciences, University of Florida. 